\title{
Ricardo Miró
}

Panamá 5, noviembre, 1883; 2, Marzo, 1940)

La vida literaria de Panamá era una parte de la de Colombia hasta I903, en que se realiza la independencia del Istmo. Después, aunque se lo disputaran influencias de diverso género, en especial las de Notteamérica, Panamá siguió fiel a la tradición cultural de Colombia. La asistían en este propósito, indiscernibles razones. Una de ellas el permanente vínculo con Bogotá, foco de su saber.

Ricardo Miró Denis, tenía sangre de liridas: su tía (Amelia Denis, hermana de Mercedes, la madre del poeta) se consagró a las letras. Entre I883 ( 5 de noviembre) fecha de su nacimiento y 1898 , Ricardo Miró vivió dentro del ambiente calino y fulgurante del Istmo. No eran dias propicios a la literatura. Y aunque ya se insinuaba el lirismo de Darío Herrera, insigne modernista, debemos convenir en que, por ausencia de acicates inmediatos, la vida artística era en Panamá de aspecto y contenido subsidiarios. Hay un hecho ajeno a la literatura, que sin embargo influyó determinantemente en ella: la apertura del llamado Canal Francés. Según es sabido, una Compañía Francesa, dirigida por Ferdinand Lesseps, que había tenido la gloria de abrir el Canal de Suez, obtuvo la buena pro para coronar tal empresa. Fue un fracaso. Se introdujo en Panamá entonces una auténtica esclavitud de negros barbadenses, jamaicanos, bahamenses, antigueños, colombianos. No obstante la reducida tasa de gente culta, que hubo entre ellos, en cierta medida, aquella inmigración contribuyó a dar a conocer modelos directos del modernismo. Como en tierras del trópico, la pasión pudo siempre más que la intelección, Panamá hubo de experimentar esa presión no siempre deseable. Los que hablan de la "generación literaria de 1894" en América Latina, pretenden ignorar ex-profeso la decisiva influencia del clima y las costumbres locales, como se ve en el caso de Centroamérica. El hecho es que Ricardo Miró Denis, emigró de Bogotá, para cultivarse; al poco 
tiempo volvió al Istmo, en donde, al menos, no eran tan perceptibles los efectos de la cruenta Guerra de los Mil Días, trabada entre los liberales y conservadores de Colombia.

El desenlace de aquella lucha, en lo que a Panamá corresponde, fue la creación de la República. Acaeció el suceso el 3 de noviembre de I903; Ricardo Miró, ya de regreso de Colombia, cumplía los veinte años. No titubeó en adherirse al movimiento de exasperado nacionalismo suscitado a raíz de la Independencia. Al año siguiente aparecía El Heraldo del Istmo dirigido por Guillermo Andreve, uno de los capitanes del modernismo panameño. ${ }^{1}$

He leído con atención casi todos los números de ese periódico, en el que afloraran, un poco a destiempo, los primitivos modos del rubendarismo. El mundo de aquellos escritores estaba poblado de ninfas y faunos, de marquesas y pastorales. Mantenían el tono de Prosas profanas cuando ya el autor de este libro había variado radicalmente de tendencia. Se explica esto en gran parte por las características del trópico y por las circunstancias especiales de Panamá, atareado en ese momento por dos ocupaciones fundamentales: instrumentar la recién nacida república y encarar todo lo concerniente a la apertura del Canal. No era el instante más propicio para la deleitosa creación literaria, sobre todo, para la creación formalista del Modernismo. Por otro lado, la propia situación istmeña instaba a liberarse de los fenicios del día para rescatar o resguardar el tesoro espiritual en peligro. Ricardo Miró se unió al grupo en que, además de Andreve, el más dinámico, figuraban Darío Herrera, Adolfo García y el joven Enrique Geenzier.

Rodrigo Miró, su puntual biógrafo, hijo y exégeta, nos refiere que Ricardo contrajo matrimonio en 1906 , y que al año siguiente, se produjeron dos acontecimientos en su vida: La aparición de la revista Nuevos ritos, en que sustituyó al capitanazgo de Andreve, y el fugaz trato con Dario, al paso de éste por Panamá, de regreso de la Conferencia Panamericana celebrada en Río de Janeiro, de la cual queda, como magnífico airón la "Epístola a Madame de Lugonés" ("Madame de Lugonés, j’ai comencé ce vers..."). Acto seguido Miró publica su primer libro: Preludios (rgo8).

Miró era entonces lo que suele llamarse un joven prodigio. El Gobierno y la sociedad panameña elogiaban al joven apolonida. Para aplicar sus posibilidades, se le nombró diplomático en Inglaterra. Miró

1 Rodrigo Miró, Introducción a la Antología poética de Ricardo Miró, Guatemala, ed. del Gobierno, 1951, p. xvi-xxxv. 
deja pasar tres años viajando entre este país, España y Francia, pero sobre todo residiendo en Barcelona, donde conoció a Santiago Rusiñol, Pompeyo Gener y el colombiano Vargas Vila. De ellos aprende la fácil ciencia del apóstrofe y la más difícil del sentimentalismo. Cuando encuentra a Filippo Marinetti, el padre del futurismo, la personalidad de Miró, aunque porosa, se halla impenetrable a los delirios automatistas de la nueva y estridente escuela literaria.

La peripecia biográfica de Miró es muy precisa desde entonces: vuelta a Panamá en I9II; reincorporación a la revista Nuevos ritos, publicación de Los segundos preludios (I9I6); director de los Archivos $\mathrm{Na}$ cionales (I919); miembro de la delegación panameña al Primer Centenario de la Independencia del Perú (julio de I92I); secretario perpetuo de la Academia Panameña de la Lengua (I926); renuncia de los Archivos (1927); publicación de Caminos silenciosos (r929); dedicación a escribir más versos, cuentos, dramas y finalmente la muerte el 2 de marzo de I940, siempre en la ciudad de Panamá, a la que estuvo como adherido.

En Ricardo Miró se magnifican las virtudes y los defectos del modernismo, del cual precisamente alzaba sus banderas. Los temas de Miró no se apartan de los predilectos de nuestros románticos, agravándose al contrario con sobrecarga de nacionalismo inucitable en esa hora en que nacía la nueva República. Miró se ciñe al cartabón de los sonetos lugonianos, en especial los de la etapa de Los creprísculos del jardín, coincidentes con los de Herrera y Reissig, el de Los peregrinos de piedra. Los de Miró aparecen como saturados de sensaciones y emociones exclusivamente eróticas. Por ejemplo, este primer cuarteto del soneto "Copos de espuma", datado en I905:

Bajo el palio nupcial de tus amores, sobre la grama del jardín dormido, hallé en tu boca delicado nido para arrullar mis pálidos ardores.

Cualquier crítico impugnaría la expresión "pálidos ardores" por ilógica y de discutible buen gusto. No es eso lo saltante, sino la anacrónica combinación de acentos que modifica el endecasílabo ritual, mezclando los acentuados en la sexta sílaba, con los acentuados en la cuarta y octava, y en especial la forma del último terceto, que condensa, como en una pincelada final, la inspiración entera de la estrofa: 
$Y$ en el cansancio azul de tu pupila

fue la noche como una mar tranquila que se rizara con espumas de oro.

La frase "el cansancio azul de tu pupila" luce, por doble vía, la impronta modernista: primero, en el uso del "azul" y, segundo, en el tropo sutil "cansancio azul de tu pupila", que reemplaza con ventaja el empleo de los vocablos "languidez de tu mirada" y otros similares, al cabo de tanto uso absolutamente deplorables.

Ricardo Miró fue, empero, un repentista, con esa facilidad para soñar y rimar típicas en el hombre del trópico. Por ende, sufrió esa peligrosidad para caer en el mál gusto, característico del repentista. No suele abundar en las latitudes ecuatoriales el tipo del poeta cuidadoso, meditativo, racionalista, al modo de Saint-John Perse, Elliot o Valéry. Predomina el sensitivo, el sentidor. En el caso de Miró, y a causa tal vez de la deslumbrante luz de la región istmeña, se destaca un ágil impresionista. Sus versos son como cortas pinceladas o vigoroso brochazo. Rara vez concluye Miró un cuadro. Suele dejarlo insinuado, inconcluso.

Ha dicho Rodrigo Miró, su mejor glosador, que en Ricardo es notoria la insistencia en el tema de las garzas. Así ocurre, pero, en realidad, al hacerlo Miró recoge un tema esencialmente panameño. La garza es para ese país como el cóndor para la región andina, el loro para la selva de América Central, o el puma y el boa para la jungla amazónica. Miró admira y canta con delectación a la garza. Lástima que el léxico no iguale al ímpetu sentimental. La frecuencia de los verbos "enloquezco", "me enamoran", acusan cierto déficit en el vocabulario. No obstante, hay algunas estrofas en que casi desaparecen los excesos sonoros y las pobrezas de léxico:

Pero yo amo las garzas porque existe un amable recuerdo en mi memoria, es el tuyo: tú fuiste blanca y triste, $y$, volando en silencio, te perdiste en el cielo sin nubes de mi historia.

La fecha es 1907; Miró tenía veinticuatro años, pero demasiada vehemencia por prefigurar sus apetencias y soñaciones. De otra suerte habría evitado los escollos poéticos significados por palabras tales como "amable", "sin nubes", y no habría insistido en algunas constructivas consonancias interiores como la del verso tercero. 
Miró fue un bohemio, en el sentido decimonónico de la palabra. Le gustaba deambular; a menudo, los amores de paso; no pocas veces, el buen beber; siempre, en extraño contubernio, le rodearon la soledad esencial y la amistad barata. Vivía sí; eso es: vivía y cantaba, sin importarle mucho lo que dijera la crítica, demasiado seguro de la potencia de su garganta, de la fineza de su oído. Se envolvía en una niebla de pesimismo y hastío, muy de acuerdo con la actitud de aquel tiempo; presa de un dandysmo no siempre de la mejor cepa. En la composición "Poemas dolorosos", pertenecientes a Caminos silenciosos, se halla como en ninguno de sus versos la verdad del lirida:

¿Dolor el de quien ama a una mujer que ha sido de todos y no puede bañarse en el olvido!

Ylo la encontré en la calle como encontramos una moneda, o como hallamos, en un charco, la luna; y así como la luna se hiciera mil pedazos al tocarla, se me hizo pedazos en los brazos.

¿De qué remota estrella de amor plugo al Destino traerla y colocarla dócil en mi camino? ¿Acaso fue Dios mismo quien fraguó la ironía de hacerla suave y mansa para que fuera mía?

Mía... como la garza; mía... cual la gaviota, como la nube errante, como la errante nota.

El ritmo de este poema es realmente como un título doloroso. Tiene el aval de una angustia autobiográfica, de una experiencia vertida en el tentador lenguaje del verso. Mas, aparece, al mismo tiempo, una de las debilidades de la poesía de Miró: su falta de pulimiento, su confianza en sí mismo, en su impulso inicial. Ello se advierte de nuevo, y con mayor nitidez en el "Responso a Margarita Krotsky", en el que, entre muchas concesiones imperdonables al tintineo de la rima, encontramos esta estrofa señoril:

Pero, imposible fue que entre los dos

floreciera el amor con sus espinas, porque nos lo vedaron las divinas y sabias manos de Dios. 
'En general, Ricardo Miró se consagra a temas demasiado trillados, por respetables o altos que sean: mujer, amor, patria, paisaje regional. En lo uno y lo otro, pone un insistente acento confidencial. En realidad, a semejanza de Chocano, a quien imitó en determinados instantes y a quien rindió pleito y público homenaje, no concibe el mundo ni la vida sino a través de su propia experiencia, de su pasión del día. El lirismo se le convierte en agudo subjetivismo. Podría decirse igual de Byron, Espronceda, Musset, pero, guardadas las distancias, aquellos pertenecen a una etapa absolutamente romántica, mientras que Miró se desarrolla en la del modernismo, cancelados el romanticismo y hasta el simbolismo. Además, considerada su larga permanencia en Europa y su contacto con Marinetti y Maristany, ¿cómo fue posible que no reaccionase contra un temario anacrónico y hasta absoleto como el de su uso?

Surge aquí una cuestión: ¿cuánto y qué leyó este hombre? Porque un poeta se perfecciona y alisa a través de sus lecturas. Estas constituyen su alimento, su pista de ejercicio, su modo de crecer. Las lecturas perceptibles a lo largo de la obra de Miró son pocas y no muy significativas. Desde luego, Rubén Dario, José Santos Chocano, Guillermo Valencia, José Asunción Silva, entre mus más asiduos modelos modernistas, y Gustavo Adolfo Bécquer y Ramón de Campoamor, entre los españoles. No cabe duda de que frecuentó autores franceses y probablemente ingleses, pero siempre dentro de la escuela romántica y aún parnasiana. Es lo que traslucen sus versos.

Pertenecía Miró a un tipo de escritor finisecular. Prefería vivir y conversar a leer y estudiar. Sus aciertos provienen de la intuición, de un rapto de inspiración.

Esta actitud, lindante con el romanticismo, aparece con nitidez en este terceto:

$¡$ Historia de mi vida compendiada, porque yo soy, cual la gaviota aquella, ave dejada atrás por la bandada!

Como todo bohemio, prefería dejar libre paso a sus emociones e impresiones, que acendrarlas, depurarlas y perfeccionarlas. Su obra es toda ella, como la gaviota de su símil, volandera e intensa, solitaria y velada de tristeza. Con ese intransferible dejo de melancolía que se oculta siempre bajo la gárrula apariencia de un vivir al desgaire, sin prejuicios, en realidad aterido del temor de no pasar sin huella, pero al 
mismo tiempo, por la urgencia de pasar pronto, resignadamente, con ese fatalismo esencial de los bohemios. La obra de Miró, la más importante en la poesía panameña hasta que apareció la nueva generación, en que destacan Ricardo Bermudez, Eda Nela y otros, corre parejas con la de Olimpia de Obaldía y Demetrio Korsi, todos ellos aquejados del mal de la nostalgia amoraca, según suele ocurrir en los posrománticos. Si en el conjunto de la poesía americana no acusan un signo ampliamente favorable, representan, de todas maneras, un modo de concebir la vida y la poesía en un sector de América: encarnan su manera de reaccionar estéticamente. Como en el campo de la vida cívica, representan una especie de caudillismo improvisador, gallardo, desigual y emotivo. El tiempo, los contactos culturales, la evolución colectiva e individual irían haciendo el resto. El resto que ahora es el núcleo del que irradian nuevas tendencias y una sutilísima poesía a menudo más bien metafísica que descriptiva, a despecho de realizarse en el trópico, donde por lo común predominan los elementos exteriores, arrasando con excesiva frecuencia las calidades y perplejidades íntimas de que se nutre sustancialmente toda poesía.

\section{BIBLIOGRAFIA}

Obras de Ricardo Miró: Preludios, Panamá, 1908; Los segundos preludios, Panamá, I9ı6; Caminos silenciosos, Panamá, I929; Antología poética, Panamá, 1937 (comp. de Rodrigo Miró); Antología poética, Guatemala, Ed. del Gobienno, I95r. Además, La voz de la raza y La leyenda del Pacífico, poemas largos en La revista nue$v a, \mathrm{y}$ otros poemas en las citadas antologías. Su obra en prosa, dis. persa en periódicos y revistas, ha sido compilada por su hijo Rodrigo.

Sobre Ricardo Miró: Miguel Amado, Precursores y rebeldes, Buenos Aires, I943; Diógenes de Rosa, Noía polémica en La Estrella de Panamá, Panamá, I3 de mayo de I937; Roque Javier Laurenza, Los poetas de la generación republicana, Panamá, I933; Ricardo Miró, Taboga (páginas autobiográficas); El Heraldo del Istmo, Panamá, 20 de septiembre de r906; Un béroe más (autobiográficas): en El Panamá América, I2 de enero, I946; Rodirigo Miró, Introducción a 
la obra poética de Ricardo Miró, en Antología poética, de R. Miró, Panamá, 1937; id. Teoría de la Patria, Buenos Aires, I947; Federico Tuño, Preocupaciones, San José de Costa Rica, I943. Hay mucha biografía y comentarios en periódicos y revistas panameñas.

Universidad de San Marcos, LuIS ALBERTo SÁNCHez Lima, Perí 